Supporting Information

\title{
Trace Cr(VI) Removal: Evidence of redox-active ion exchange by a weak base anion exchanger
}

\author{
Renuka Verma and Sudipta Sarkar* \\ Department of Civil Engineering, Indian Institute of Technology Roorkee, Roorkee 247667, Uttarakhand, \\ India \\ *srkarfce@iitr.ac.in \\ Tel.: +91-1332-284756
}

Supplemental Information Contents:

1. Chemical structures of ion exchange resins used in the study

2. Experimental setup in the laboratory

3. Column performances of different ion exchange resins for trace $\mathrm{Cr}(\mathrm{VI})$ removal at influent $\mathrm{pH} 7$

4. Speciation diagram of aqueous $\mathrm{Cr}(\mathrm{VI})$ species

5. Speciation diagram of aqueous chromium

6. Thermal analysis 
1. Chemical structures of ion exchange resins used in the study

a) INDION 820

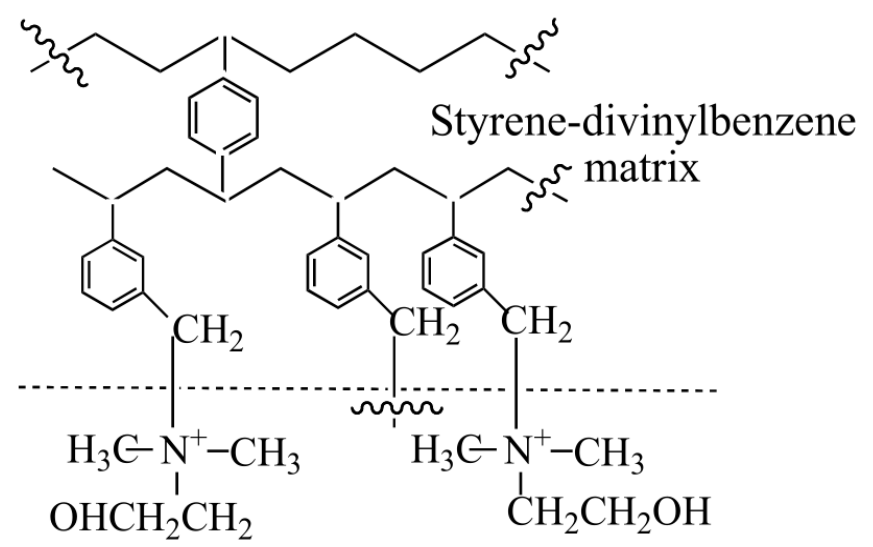

b) INDION 860

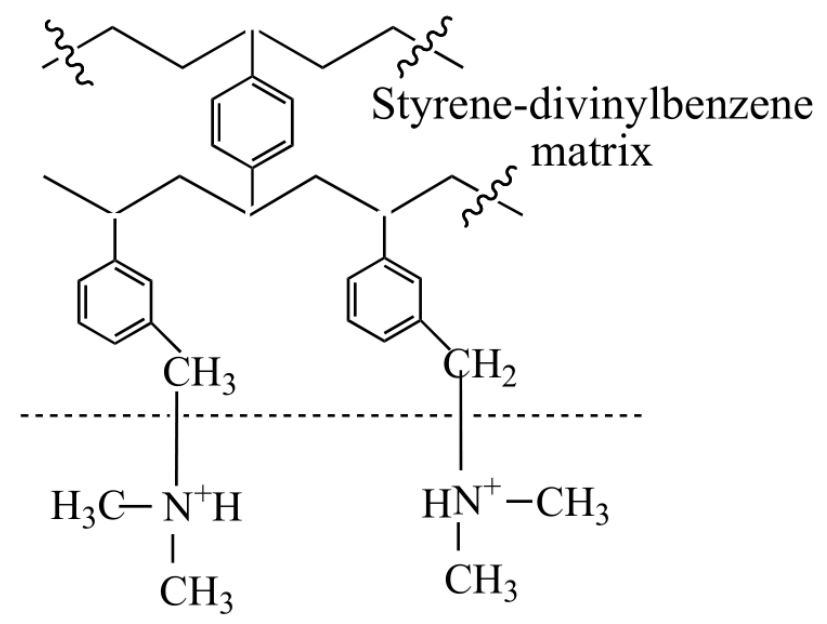

c) Amberlite IRA 67

IUPAC Name: 1,2-bis(ethenyl)benzene,4-[(E)-2-[(E)-2-but-3-enoxyethenoxy]ethenoxy]but-1ene,N-[3-(dimethylamino)propyl]prop-2-enamide

Molecular Formula: $\mathrm{C}_{30} \mathrm{H}_{44} \mathrm{~N}_{2} \mathrm{O}_{4}$

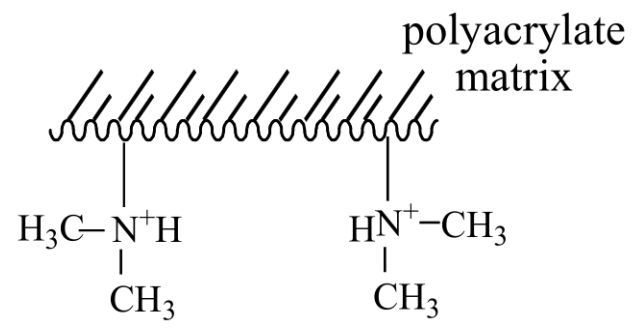




\section{d) Duolite A7}

Chemical Name: Formaldehyde, polymer with N,N'-bis(2-aminoethyl)-1,2-ethanediamine and phenol

Molecular Formula: $\mathrm{C}_{13} \mathrm{H}_{26} \mathrm{~N}_{4} \mathrm{O}_{2}$

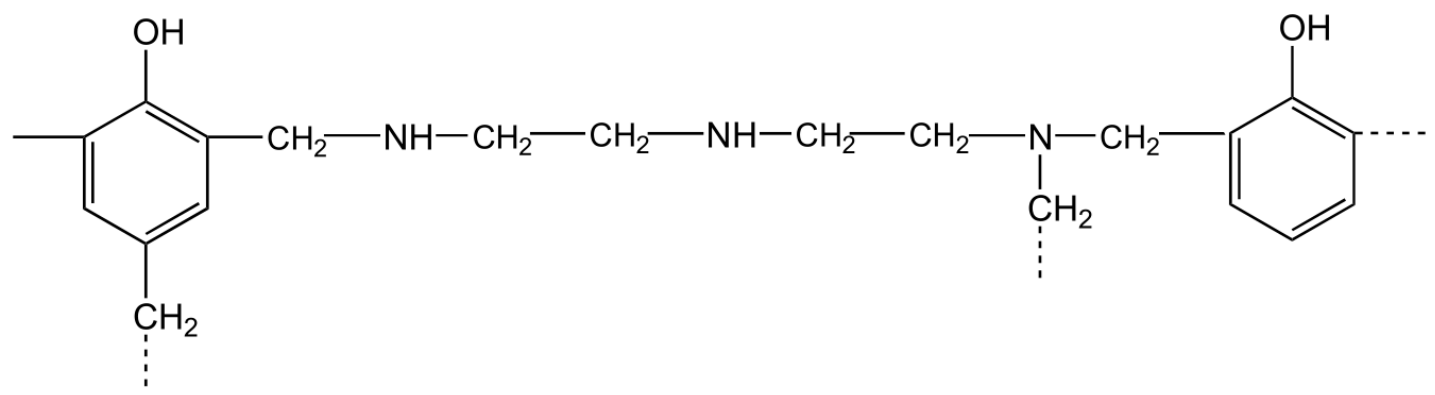

Figure S1. Chemical structures of ion exchange resins used in the study. 
2. Experimental setup in the laboratory

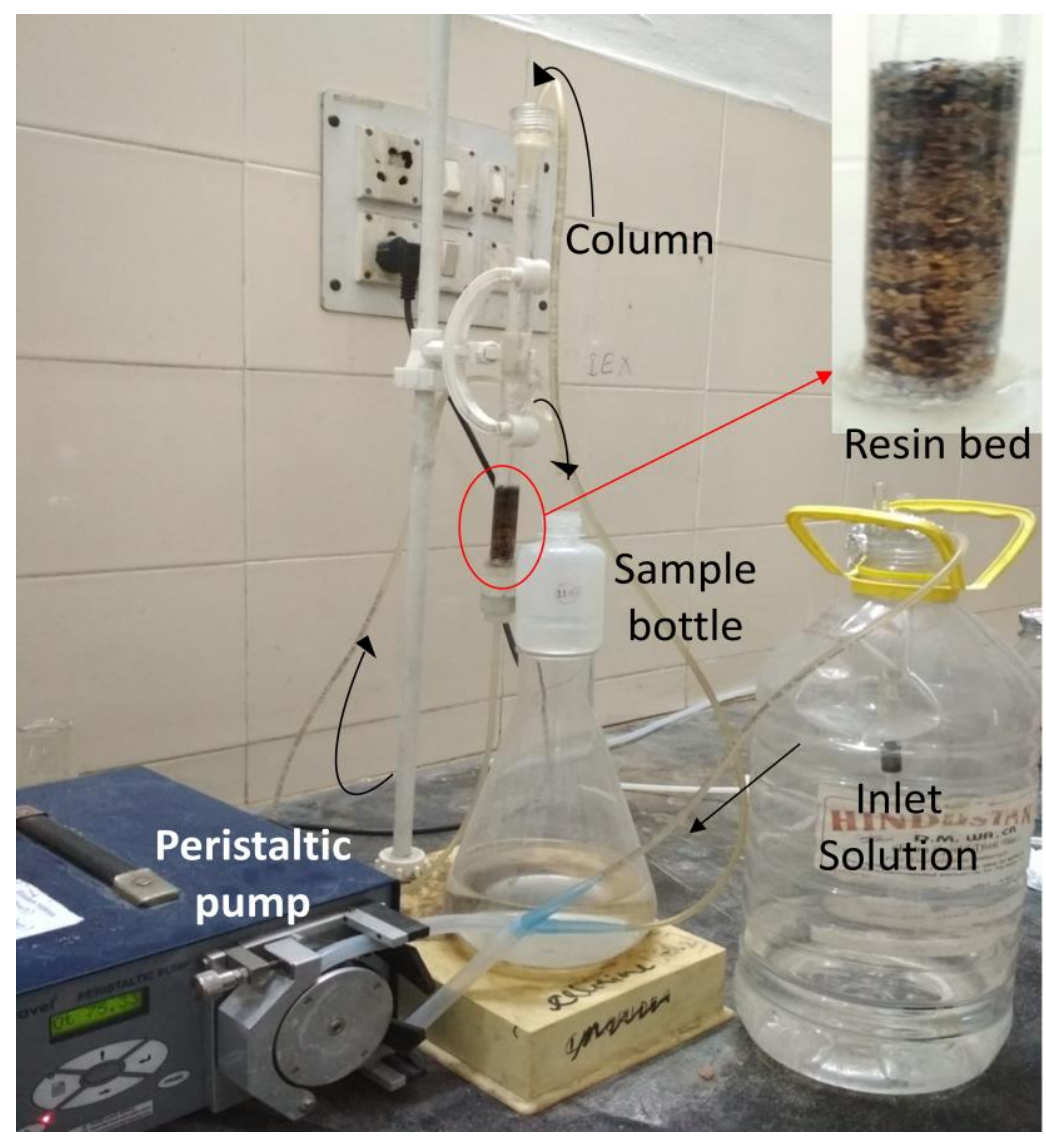

Figure S2. Experimental setup in the laboratory; $\mathrm{Cr}(\mathrm{VI})$ concentration in the synthetic raw water kept as $200 \mu \mathrm{g} / \mathrm{L}$ with a background concentration of competing anions like sulphate, chloride and bicarbonate as $100 \mathrm{mg} / \mathrm{L}$ each. 
3. Column performances of different ion exchange resins for trace $\mathrm{Cr}(\mathrm{VI})$ removal at influent $\mathrm{pH} 7$

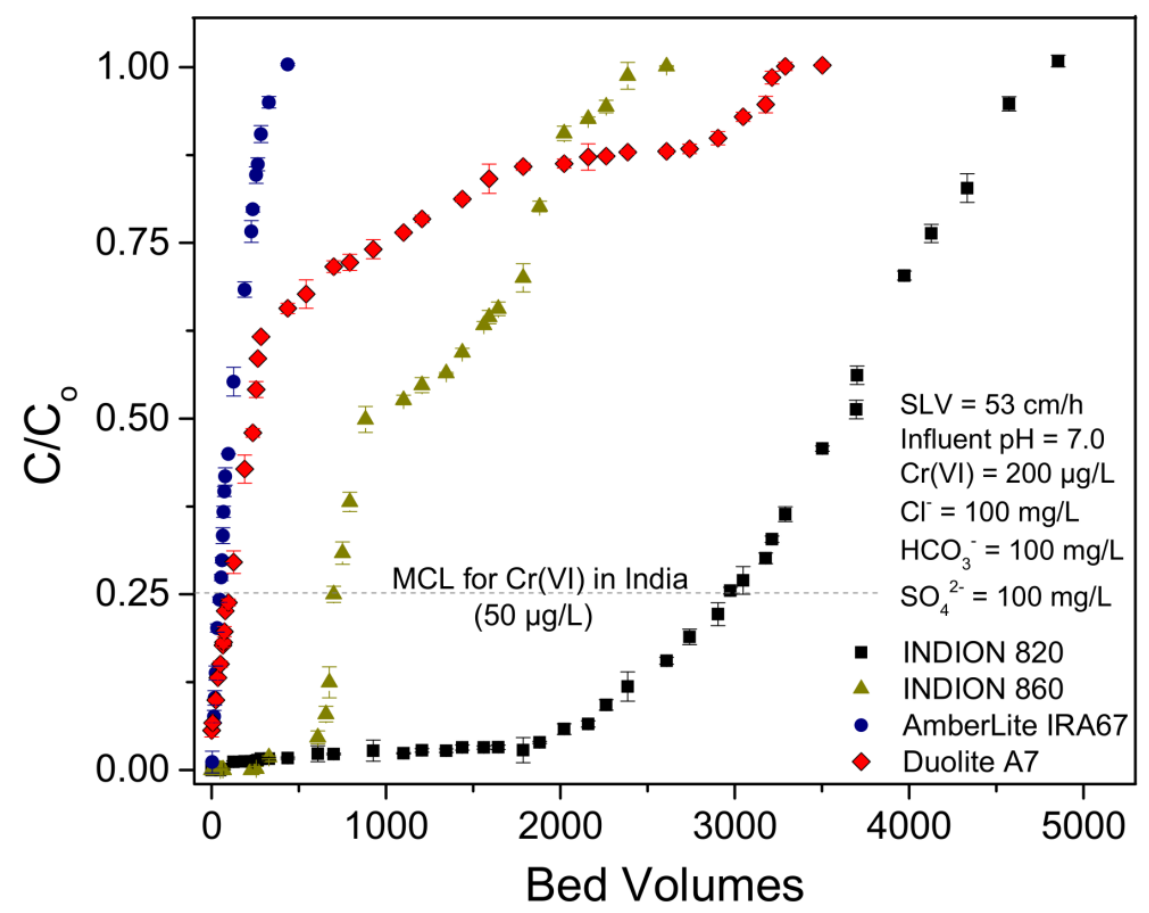

Figure S3. Chromium breakthrough profiles of column runs of strong base anion exchange resin (INDION 820) and weak base anion exchange resins (INDION 860, Amberlite IRA 67, and Duolite A7) with synthetic influent containing $\mathrm{Cr}(\mathrm{VI})$ anions in presence of competing background anions. 
4. Speciation diagram of aqueous $\mathrm{Cr}(\mathrm{VI})$ species

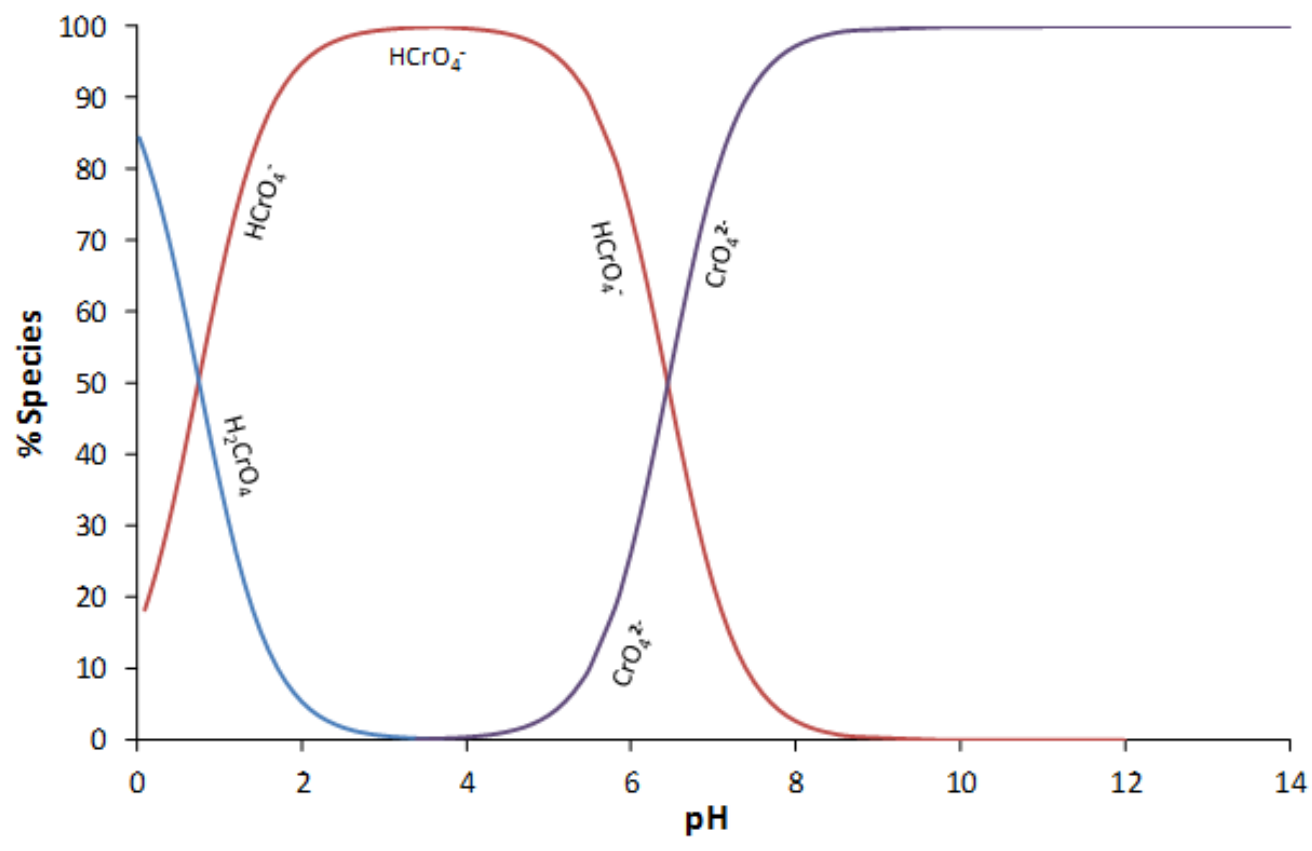

Figure S4. Speciation diagram of aqueous $\mathrm{Cr}(\mathrm{VI})$ species for $\mathrm{Cr}(\mathrm{VI})$ concentration less than $0.01 \mathrm{M}$.

The diagram was drawn using the following equilibrium equations. ${ }^{1}$
$\mathrm{H}_{2} \mathrm{CrO}_{4} \leftrightarrow \mathrm{H}^{+}+\mathrm{HCrO}_{4}^{-}$
$\log \mathrm{K}=-0.8$
$\mathrm{HCrO}_{4}^{-} \leftrightarrow \mathrm{H}^{+}+\mathrm{CrO}_{4}^{2-}$
$\log \mathrm{K}=-6.5$ 
5. Speciation diagram of aqueous chromium

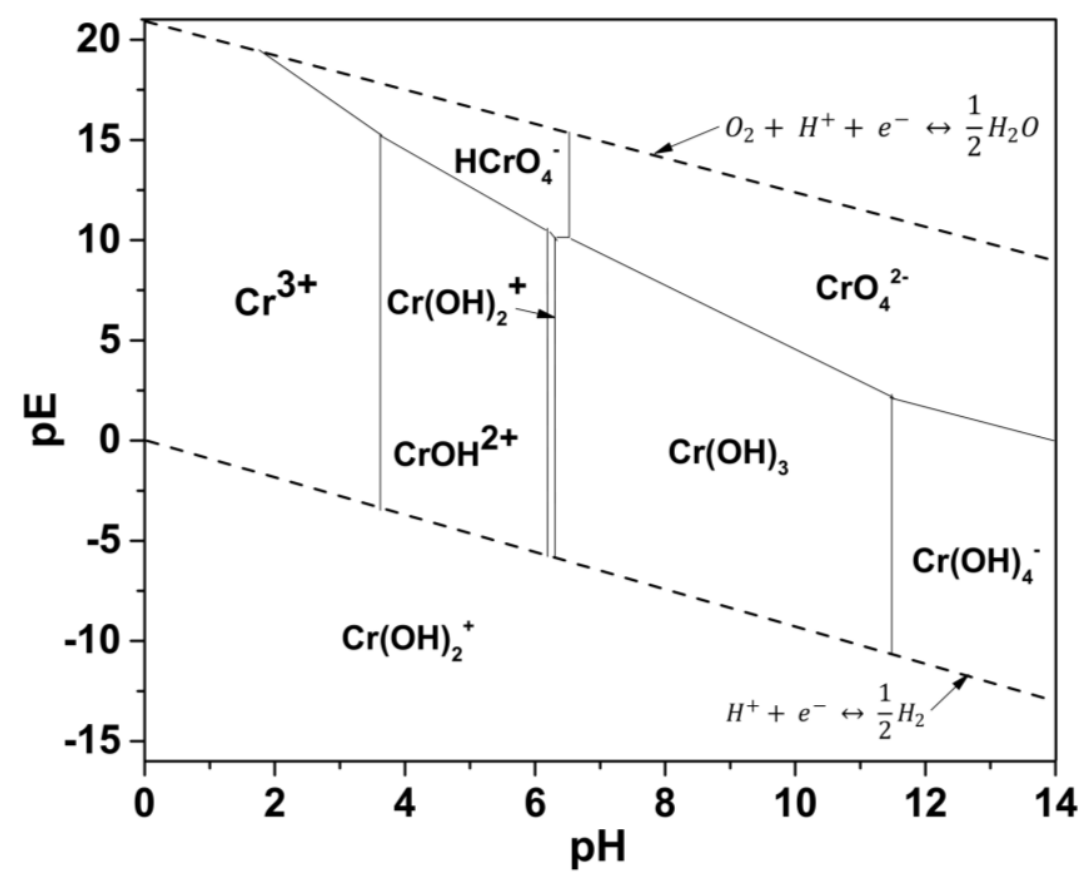

Figure S5. Speciation diagram of aqueous Chromium.

The diagram was drawn using the following equilibrium equations. ${ }^{2}$

$$
\begin{array}{ll}
\frac{1}{3} \mathrm{HCrO}_{4}^{-}+\frac{7}{3} \mathrm{H}^{+}+e^{-} \leftrightarrow \frac{1}{3} \mathrm{Cr}^{3+}+\frac{4}{3} \mathrm{H}_{2} \mathrm{O} & \log \mathrm{K}=+20.2 \\
\mathrm{HCrO}_{4}^{-} \leftrightarrow \mathrm{H}^{+}+\mathrm{CrO}_{4}^{2-} & \log \mathrm{K}=-6.5 \\
\mathrm{Cr}^{3+}+\mathrm{H}_{2} \mathrm{O} \leftrightarrow \mathrm{CrOH}^{2+}+H^{+} & \log \mathrm{K}=-4.0 \\
\mathrm{Cr}^{3+}+2 \mathrm{H}_{2} \mathrm{O} \leftrightarrow \mathrm{Cr}(\mathrm{OH})_{2}^{+}+2 H^{+} & \log \mathrm{K}=-9.7 \\
\mathrm{Cr}^{3+}+3 \mathrm{H}_{2} \mathrm{O} \leftrightarrow \mathrm{Cr}(\mathrm{OH})_{3}+3 H^{+} & \log \mathrm{K}=-18.0 \\
\mathrm{Cr}^{3+}+4 \mathrm{H}_{2} \mathrm{O} \leftrightarrow \mathrm{Cr}(\mathrm{OH})_{4}^{-}+4 H^{+} & \log \mathrm{K}=-27.4 \\
\mathrm{O}_{2}+\mathrm{H}^{+}+e^{-} \leftrightarrow \frac{1}{2} \mathrm{H}_{2} \mathrm{O} & \mathrm{pE}^{\circ}=+20.75 \\
\mathrm{H}^{+}+e^{-} \leftrightarrow \frac{1}{2} \mathrm{H}_{2} & \mathrm{pE}^{\circ}=0.0
\end{array}
$$




\section{Thermal analysis}

Thermo Gravimetric/Differential Thermal Analysis (TG/DTA) was performed using EXSTAR Model SII 6300, under inert (nitrogen) atmosphere with temperature ranging from 35 to $650^{\circ} \mathrm{C}$ at $10^{\circ} \mathrm{C} / \mathrm{min}$ heating rate. Thermogravimetric analysis (TGA) is performed to study the variation in weight of a sample with temperature in a controlled atmosphere, which is then used to obtain information like phase changes, kinetics, or ash content of the sample.

For virgin resin, the first loss stage is observed at $30-120^{\circ} \mathrm{C}$ which is due to evaporation of water that is chemically adsorbed in the porous network and release of low molecular weight compounds. The second loss stage occurred at $130-360^{\circ} \mathrm{C}$ due to formaldehyde release from dimethylene ether bridges that are transformed into methylene bridges. ${ }^{3,4}$ The weight loss above the temperature of $360^{\circ} \mathrm{C}$ is attributed to the rupture of methylene bridges and degradation of the phenolic network. ${ }^{3,4}$ It is also depicted by the primary decomposition peak at $397^{\circ} \mathrm{C}$ of the DTG curve. About $49 \%$ is left as a solid residue which shows that the resin has good thermal stability. DTA curve showed that exothermic reactions took place throughout the process but there was no rapid reaction and the negligible thermal effect was observed after $450^{\circ} \mathrm{C}$. After $\mathrm{Cr}(\mathrm{VI})$ loading, the first loss stage was observed at $30-200^{\circ} \mathrm{C}$ and similar behavior has been reported in previous studies. ${ }^{5}$ DTA curve shows a significant three-stage weight loss of the sample observed at 245, 333, and $501^{\circ} \mathrm{C}$. All these reactions are exothermic in nature. The peaks at 245 and $333^{\circ} \mathrm{C}$ can be attributed to formaldehyde release from dimethylene ether bridges that are transformed into methylene bridges. ${ }^{3}$ The peak at $501^{\circ} \mathrm{C}$ is due to thermo-oxidation of resin, i.e., breakage of aromatic rings releasing gaseous products like $\mathrm{CH}_{4}, \mathrm{CO}_{2}, \mathrm{CO}$, etc. In the case of exhausted resin, only $4 \%$ residue is left. These results indicate that chromium might have interacted with the matrix of the resin and formed complexes that have altered the thermal behavior of the resin. 

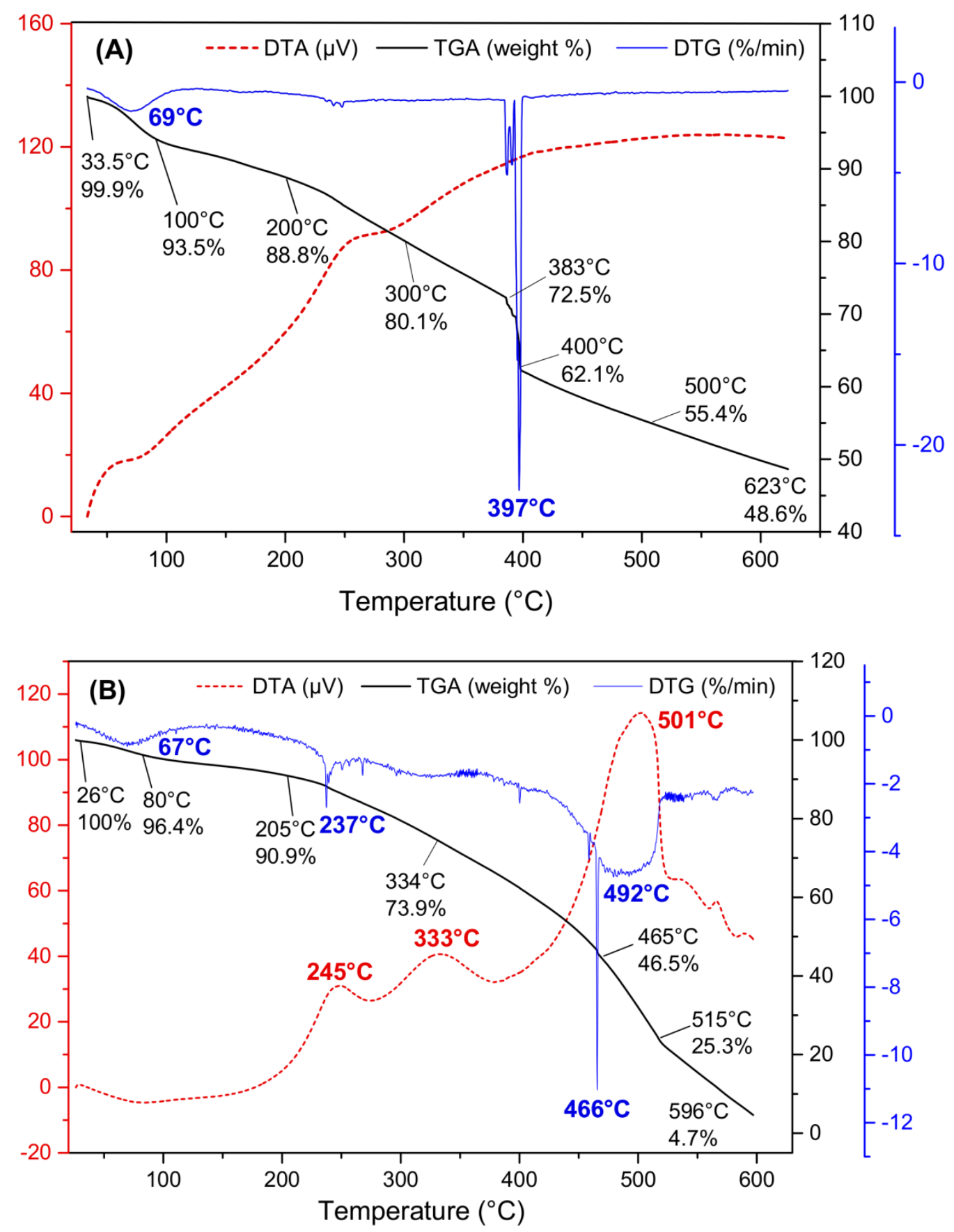

Figure S6. Thermal curves of (A) virgin Duolite A7 resin and (B) exhausted Duolite A7 resin collected from column running at influent $\mathrm{pH} 7$, under nitrogen atmosphere. 


\section{References}

1. Sengupta, A. K.; Clifford, D. Important Process Variables in Chromate Ion Exchange. Environ. Sci. Technol. 1986, 20, 149-155.

2. Rai, D..; Sass, B. M.; Moore, D. A. Chromium (III) Hydrolysis Constants and Solubility of Chromium (III) Hydroxide. Inorg. Chem., 1987, 26, 345-349.

3. Bouajila, J.; Raffin, G.; Alamercery, S.; Waton, H.; Sanglar, C.; Grenier-Loustalot, M. Phenolic Resins (IV). Thermal Degradation of Crosslinked Resins in Controlled Atmospheres. Polymers and Polymer Comp. 2003, 11, 345-357.

4. Papadopoulou, E.; Chrissafis, K. Thermal study of phenol-formaldehyde resin modified with cashew nut shell liquid. Thermochim. Acta 2011, 512, 105-109.

5. Chang, X.; Li, M.; Liu, Q.; Qinze Liu; Yao, J. Adsorption-reduction of Chromium(VI) from aqueous solution by phenol - formaldehyde resin microspheres. $R S C A d v$. 2016, 6, 4687946888. 